\title{
SEQUENTIAL STUDY OF BACTERIAL CLEARANCE IN EXPERIMENTAL CYSTITIS
}

\author{
G. Gillon, M. SMall*, O. Medalia* and M. Aronson*† \\ Department of Urology, Beilinson Medical Center, Petach Tikva and *Department of \\ Histology and Cell Biology, Sackler School of Medicine, Tel-Aviv University, Ramat \\ Aviv 69978, Israel
}

\begin{abstract}
Summary. Clearance of Escherichia coli in experimental cystitis was studied in the diuresing mouse model. Urine was collected daily; sediment was isolated by cytocentrifugation and either stained or treated with fluorescent antibodies directed against mouse immunoglobulins. During the initial phase of the infection the bacteria were either free and dispersed or adhering to epithelial cells but not generally to polymorphonuclear cells (PMNs). Subsequently, the bacteria adhered to each other, to epithelial cells and to PMNs, were phagocytosed by the latter and showed strong fluorescence. It is postulated that the appearance of opsonising and agglutinating antibodies in conjunction with activity of the PMNs is involved in bacterial clearance.
\end{abstract}

\section{INTRODUCTION}

The mechanisms that prevent the development of urinary-tract infection (UTI) have been intensively studied during the past decades. They include slime formation by the bladder epithelial cells (Parsons, Stauffer and Schmidt, 1980), urinary flow (Norden, Green and Kass, 1968), the antimicrobial effect of the bladder cells (Norden et al., 1968), low $p \mathrm{H}$, high osmolality and urea (Kaye, 1968; Hadas, Medalia and Aronson, 1977).

Much less is known about the mechanisms that operate in bacterial clearance after infection has been established. The situation is particularly problematic because the role of the two agents commonly involved in combatting bacterial infections, phagocytic cells and antibody formation, is questionable in clearance of UTIs. Chernew and Braude (1962) have shown that polymorphonuclear (PMN) cells are inefficient at the high osmolality that prevails in the renal medulla, and the presence and titre of immunoglobulins in the serum or the urine were not shown to correlate with stages of the infection (Holmgren and Smith, 1975).

Previous work from our laboratory suggests that PMNs together with locally produced immunoglobulins are engaged in bacterial clearance, the line of evidence being the following: (1) The dominant exudate cell in mice infected in the urinary tract

Received 1 Feb. 1984; accepted 22 Feb. 1984.

† Correspondence to: Professor M. Aronson, Department of Histology and Cell Biology, Sackler School of Medicine, Tel-Aviv University, Ramat Aviv 69978, Israel. 
is the PMN. When (spontaneous) clearance is reached, these cells disappear abruptly, and the dominant cells are lymphocytes and macrophages, accompanied by some plasma cells (Stadler et al., 1980; Sivan et al., 1982). (2) Mice infected in the urinary tract and allowed to recover spontaneously, show a marked reduction of the clearance time upon re-infection-from 14-30 to 7-13 days (Aronson, Medalia and Griffel, 1978). (3) The dominant exudate cells in the bladders of reinfected mice are macrophages and lymphocytes (Sivan et al., 1982). These studies were incomplete because causality could not be established in the experimental conditions used. Because the mice had to be killed to provide histological material, the sequence of events could not be worked out. The main question was whether antibody formation led to bacterial clearance or whether the bacteria were destroyed by another mechanism, after which the liberated antigenic material evoked an immune response.

In the present work we made use of the fact that our experimental UTI model employs the diuresing mouse, first devised by Freedman (1967) and later elaborated by us (Aronson, 1980). It was realised that because these animals excrete relatively large quantities of urine, the cellular content can be analysed after cytocentrifugation. Hence the sequence of events in the same animals can be followed from beginning to end. In the study attention was paid to the type and number of cells that appeared in the urine, the presence of free and cell-associated bacteria, and the presence of mouse immunoglobulins on the bacteria and the cells as revealed by immunofluorescence.

\section{MATERIALS AND METHODS}

Infection. The procedure for producing experimental cystitis has been previously described in detail (Aronson et al., 1979), and will therefore be only briefly described. Escherichia coli strain 7343, an isolate from human pyelonephritis, was injected into the bladder of anaesthesised female ICR mice. The resulting infection has been shown, by histology and by organ grinding and plating, to be confined mainly to the bladder, renal involvement being rare.

The animals were maintained on glucose-containing water which caused a considerable diuresis without, however, the urine becoming diabetogenous. Urine voided by individual mice was either plated directly on nutrient agar or collected for cytocentrifugation and analysis.

Cytocentrifugation and analysis. Urine from individual mice was obtained once a day by pooling 3-4 samples collected every $2 \mathrm{~h}$ into ice-cooled tubes; this generally yielded $0 \cdot 2-0.3 \mathrm{ml}$ of material which was centrifuged in a Shandon-Elliot Cytospin for $10 \mathrm{~min}$ at 500-700 $\mathrm{g}$. The slides were then lightly dried, fixed in methanol and stained by fuchsin or Giemsa. For antibody detection by indirect fluorescence (Weller and Coons, 1954) the slides were fixed for $10 \mathrm{~min}$ in cold $95 \%$ ethanol, rinsed in PBS and stained for 20 min in rabbit anti-mouse polyvalent immunoglobulin diluted 1 in 10 (Cedarlane Laboratories, London, Ontario, Canada). The slides were rinsed and left for $5 \mathrm{~min}$ in PBS then transferred to FITC-conjugated goat anti-rabbit globulin (Grand Island Biological Company, Grand Island, NY, USA) diluted 1 in 40. After 20 min the slides were again rinsed and left for $5 \mathrm{~min}$ in PBS, stained for $5 \mathrm{~min}$ in $0.1 \%$ Evans blue and rinsed again in PBS. The preparations were mounted under a coverslip with a mounting medium of $90 \%$ glycerol in Tris buffer $p \mathrm{H} \mathrm{9.3.} \mathrm{In} \mathrm{control} \mathrm{preparations} \mathrm{normal} \mathrm{rabbit} \mathrm{serum} \mathrm{was}$ substituted for the rabbit anti-mouse antibody. Slides were viewed through a Zeiss microscope with a $\times 40$ Neofluar objective and epi-illumination. Excitation light was of 450-490 nm, and emitted light of $520 \mathrm{~nm}$.

Collection of urine on membrane filters. Mice were held directly above a membrane filter $(0 \cdot 2$ $\mu \mathrm{m}$; Millipore) under suction, which caused the voided urine to be instantaneously filtered. The filter was then treated with Harris's hematoxylin (Merck) solution, which fixed and stained the cells. Subsequent treatment of the dry filter with immersion oil rendered it translucent, and it was viewed under the microscope when placed on a glass slide. 


\section{RESULTS}

Preliminary experiments showed that after cytocentrifugation and staining of urine of infected mice, epithelial cells, PMNs, macrophages and bacteria could be identified. The bacteria appeared as free cells, in clumps, adhering to the epithelial cells and to the PMNs, and were phagocytosed by the latter, depending on the stage of infection.

Viewing of the microscopic preparations raised the possibility that the process of cytocentrifugation might introduce artifacts by causing clumping of bacteria or their adherence to cells. Another method for visualising the cellular content of the urine was therefore developed, which consisted of direct collection of the urine on a membrane filter under suction, followed by fixation, staining and clarification (see Materials and methods). By comparison of various urine samples obtained with the two procedures it was ascertained that cytocentrifugation did not cause clumping or adherence of bacteria to each other or to other cells.

\section{Change in pattern of excreted cells with time}

The data documented here summarise the results of five experiments involving c. 100 animals. For technical reasons (lack of urine, contamination with dirt, etc.) a complete sequence was not obtained from any of the individual mice. The sequence that was obtained could be summarised and thus revealed general patterns. In other words, the group pattern was based on the accumulated results from individual mice. Analysis of the cellular content of the urine could be more easily followed if the time span of the infection (2-3 weeks) was divided into four periods: inception (1 to 4-5 days), strong response (5 to 6-10 days), peak response (11 to 15 days) and clearance.

Inception was characterised by a paucity of cells, and it was difficult to obtain enough material from the same animal day by day. Nevertheless, collectively, a rather uniform picture was obtained (fig. 1). Most bacteria were free and dispersed, i.e., generally unclumped. Some were adherent to epithelial cells, while many fewer adhered to PMNs. Most of the epithelial cells did not look viable and they probably resulted from desquamation of injured and dead cells. The bacteria that adhered to the epithelial cells also appeared non-viable as judged by staining. Fluorescent bacteria, after staining with fluorescent antibodies against mouse polyvalent immunoglobulins, were already present during the first days after the infection in some mice but not in all of them. It was, however, difficult to see non-fluorescent bacteria, hence it is not clear what proportion of the bacteria were coated with antibody.

Strong response. By 5-6 days after the injection the cellular content of the urine was considerably increased $\left(10^{6}\right.$ cells $/ 24 \mathrm{~h}$ instead of $\left.10^{4}\right)$. The main increase was in PMNs, but many epithelial cells also appeared. A considerable change had taken place in the bacteria (fig. 2). Most of them were now associated with the PMNs, either by adherence or by phagocytosis, and the free bacteria had often become clumped. Strong fluorescence was manifested by the bacterial cells in all the mice; the host cells, however, rarely showed fluorescence (fig. 3).

Peak response. The trend described above was augmented. Very large clumps of cells bridged by bacteria were also encountered (fig. 4) and occasional macrophages were seen. Typically, nests of highly fluorescent bacteria appeared against a background of aggregated PMNs, usually after the 10th day after infection. 


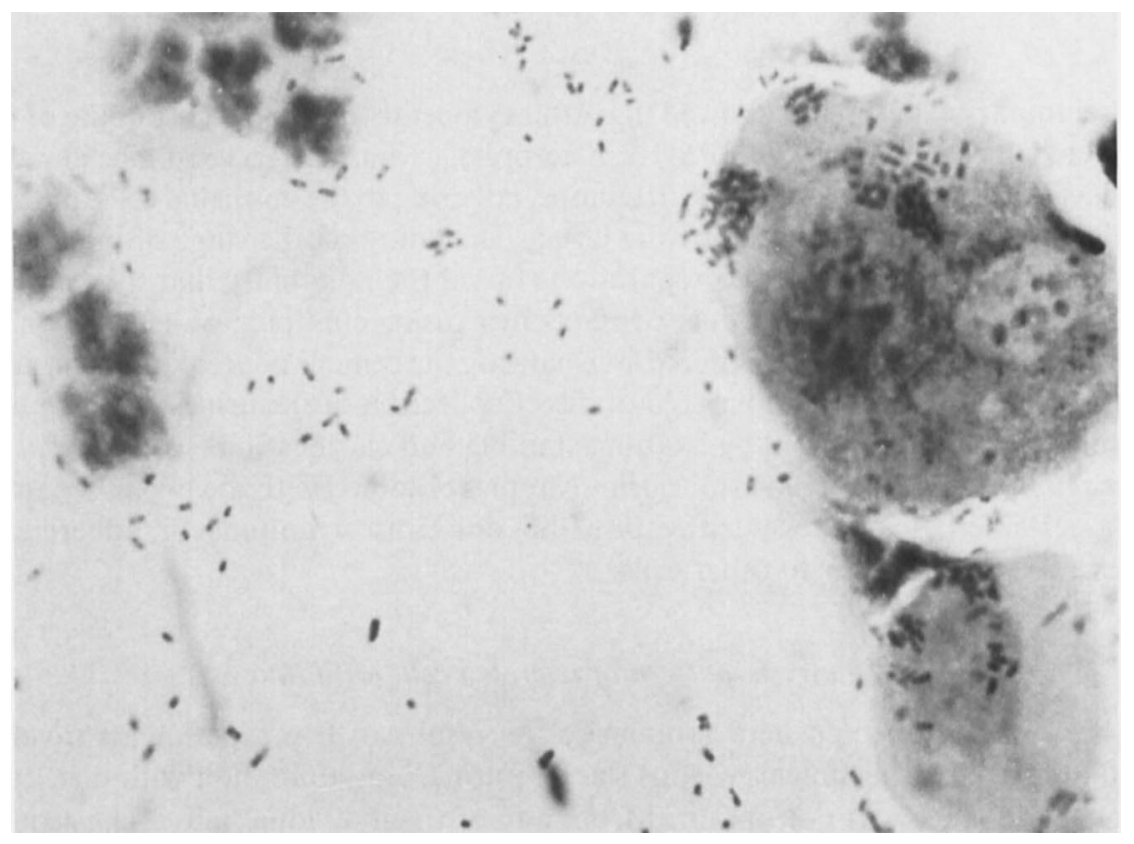

FIG. 1.-Cytocentrifugate of mouse urine at the initial stage of infection. The bacteria are either free or associated mainly with epithelial cells. Fuchsin stained. $(\times 3500)$.

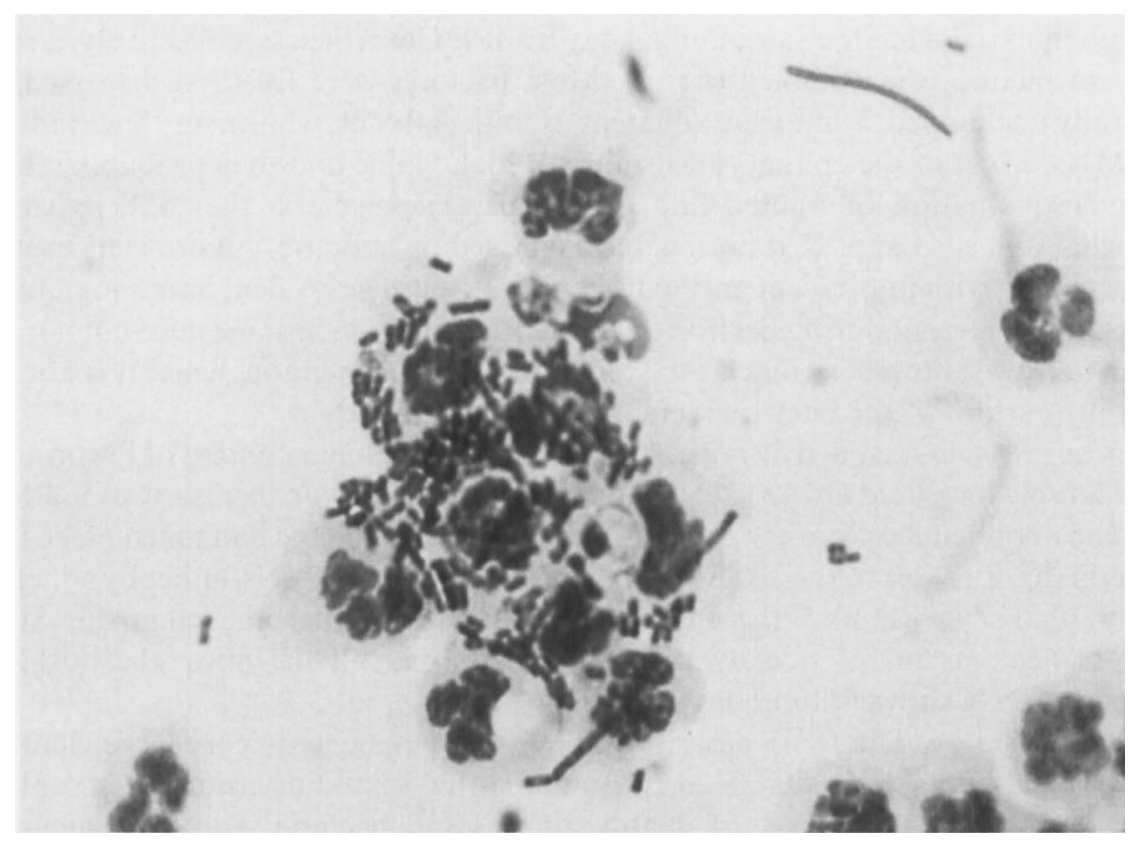

FIG. 2.-Cytocentrifugate taken one week after inception of infection. Fuchsin stained. $(\times 3500)$. 


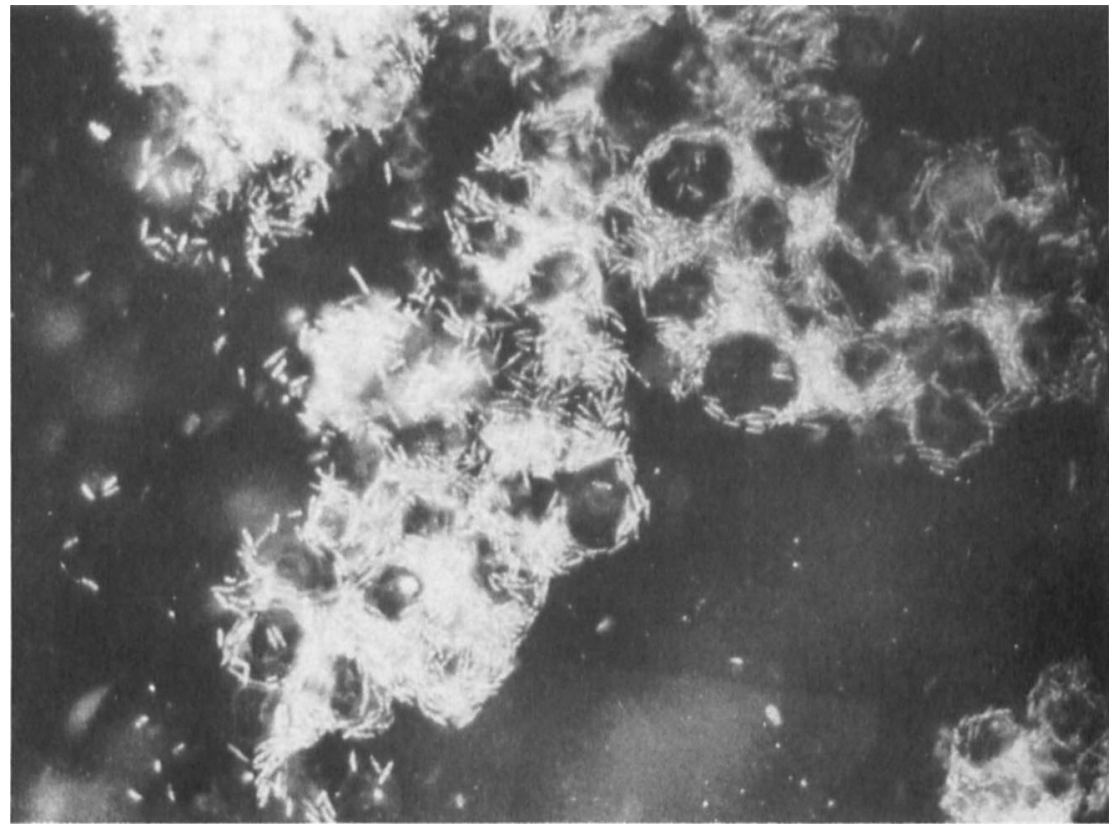

Fig. 3.-Cytocentrifugate taken one week after inception of infection. Indirect fluorescent staining. $(\times 1400)$.

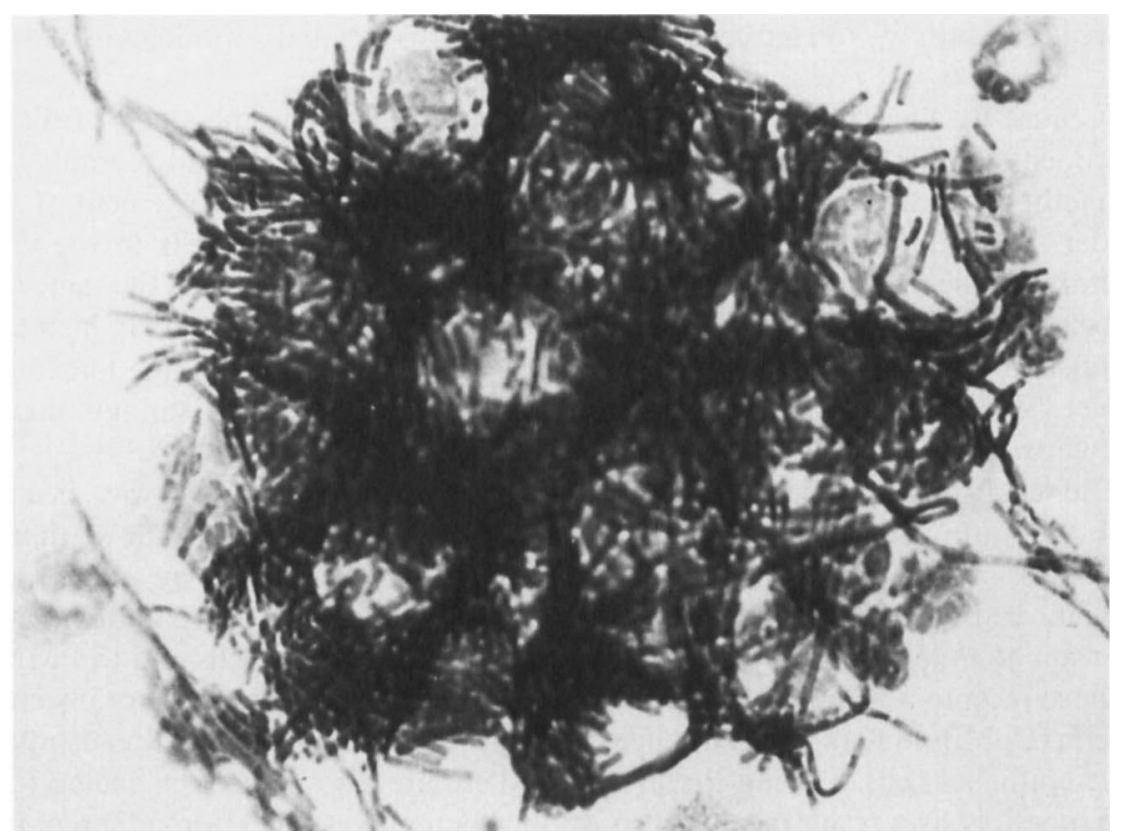

FIG. 4. - Cytocentrifugate taken 15 days after inception of infection. Fuchsin stained. $(\times 3500)$. 
Clearance. The final stage leading to a completely sterile and cell-free urine was reached either gradually or rather abruptly; in the latter case there were no clear markers to indicate that the infection was reaching its termination. The following pattern of clearance was observed in these experiments. Most of the animals shed about $10^{6}$ bacteria/ml and excreted 5-10 ml of urine per day for 16-18 days. After this period $c .75 \%$ of them began to show a consecutive reduction in the number of excreted bacteria, of about a hundred-fold per day, and the urine became sterile at 20-24 days. Another $20 \%$ of the animals displayed abrupt clearance at 18-20 days, while 5\% continued to excrete bacteria for about a month, and the urine gradually but eventually became sterile. Another $5-10 \%$ of the animals shed $10^{3}-10^{5}$ bacterial $/ \mathrm{ml} /$ day from the start, and underwent a gradual process of clearance which occurred earlier (10 days) than in the other animals. These animals, therefore, were not included in these results.

\section{Control Studies}

India-ink or suspension of non-virulent $\left(\mathrm{U}^{+}\right), E$. coli were injected instead of the test strain. The animals were checked daily for the appearance of a cellular response in the urine for a full week. Because the response was insubstantial, the dose of the $\mathrm{U}^{+}$ strain was increased tenfold $\left(10^{7} /\right.$ mouse). This resulted in only occasional appearance of some PMNs for a few days.

\section{DisCUSSION}

For this study we developed a new method to follow sequentially the process of infection and the responses of the bladder. Urine collection and cytocentrifugation allowed us to follow excreted cells and bacteria with associated antibodies in individual mice.

Because we have formerly used conventional histology in the study of the same experimental system, it is possible to compare the advantages and shortcomings of the two methods. Histological sections are informative about the involvement of all the bladder tissues and about the spatial relations of the exudate cells to the various structures of the bladder. A serious drawback stems from the fact that the same mouse can be studied only once; in addition, it is very difficult to see bacteria in histological sections, and information cannot be obtained on the cells shed into the lumen of the bladder. While the new technique cannot replace conventional histology, it can fill these gaps.

The results in the present work can be interpreted in the following way, bearing in mind that attachment of bacteria to host cells is mediated by more than one mechanism. Upon injection of the bacteria into the bladder, they adhere to the epithelial cells. The strain of $E$. coli that was used is strongly mannose sensitive (Aronson et al., 1979) and, therefore, can adhere to epithelial cells and to PMNs via mannose receptors. The PMNs however, appear only several hours after injection of bacteria (Cobb and Kaye, 1967), hence the initial inoculum must have already attached to the epithelial cells. During the first days there are also many free bacteria in the urine, possibly as a result of phase variation which makes them non-adherent (Ofek, Mosek and Sharon, 1981). 
This picture contrasted strongly with that obtained at the peak response, when the number of PMNs was greatly increased. This increase should be attributed, at least partially, to the increased vascularisation of the infected bladder (Sivan et al., 1982) which permits a quicker supply of PMNs. The bacteria at this stage appeared mostly in clumps; they adhered to the PMNs and were also phagocytosed by these cells.

It is speculated that with the appearance of opsonising antibodies the PMNs adhere to the bacteria and engulf many of them. Likewise, in the presence of agglutinins the bacteria adhere one to the other, or they even grow in clumps without separating. Considering the fact that millions of PMNs are shed daily into the urine at this stage, many of which carry large numbers of bacteria intra- and extracellularly, large numbers of bacteria are removed by the PMNs. PMNs are not efficient killers at the high bladder osmolality, but it is important to realise that there is no need on the part of the PMN that adheres to or internalises bacteria to kill them. All that is needed is migration into the lumen and thence to the urine. Urine flow would also more easily remove clumps of bacteria than single cells. Hence the co-operation of epithelial cells and particularly PMNs and of opsonising and agglutinating antibodies seems to be instrumental in clearance. This notion is in accordance with our previous findings; however, it is only in the present work that the appearance of mouse immunoglobulins on the bacteria was shown to precede clearance. Studies are now in progress in our laboratory to elucidate the order of appearance of various immunoglobulins on the bacteria: IgM, various types of IgG and IgA. Also we have just begun to study clinical cases of human cystitis by the same technique.

While the final stage was reached in some animals after gradual diminution of bacteria, in other animals no specific indication preceded clearance, which was abruptly attained. We assume that in both groups clearance was achieved when the rate of bacterial expulsion exceeded the rate of their multiplication.

We thank Dr Moshe Wolman for the free use of his fluorescence microscope.

\section{REFERENCES}

Aronson M, Medalia O, Griffel B 1978 Enhanced resistance of the urinary tract to re-infection. In: Kass E H, Brumfitt W (eds) Infections of the urinary tract. University of Chicago Press, Chicago. pp 236-242.

Aronson M, Medalia O, Schori L, Mirelman D, Sharon N, Ofek I 1979 Prevention of colonization of the urinary tract of mice with Escherichia coli by blocking of bacterial adherence with methyl- $\alpha$-D-mannopyranoside. Journal of Infectious Diseases 139:329-332.

Aronson M 1980 Experimental models of urinary tract infection: methodology and interpretation. In: Losse H, Asscher A W, Lison A E (eds) Pyelonephritis, vol. IV: urinary tract infections. George Thieme Verlag, Stuttgart, pp 21-25.

Chernew I, Braude A I 1962 Depression of phagocytosis by solutes in concentrations found in the kidney and urine. Journal of Clinical Investigation 41:1945-1953.

Cobb C G, Kaye D 1967 Antibacterial mechanisms in the urinary bladder. Yale Journal of Biology and Medicine 40:93-108.

Freedman L R 1967 Experimental pyelonoephritis. XIII. On the ability of water diuresis to induce susceptibility to $E$. coli bacteriuria in the normal rat. Yale Journal of Biology and Medicine 39:255-266.

Hadas H, Medalia O, Aronson M 1977 Differential susceptibility of Escherichia coli and Proteus mirabilis to mouse urine and to urea. Journal of Infectious Diseases 136:100-103.

Holmgren J, Smith J W 1975 Immunological aspects of urinary tract infections. Progress in Allergy 18: 389-352. 
Kaye D 1968 Antibacterial activity of human urine. Journal of Clinical Investigation 47:2374-2390.

Ofek I, Mosek A, Sharon N 1981 Mannose-specific adherence of Escherichia coli freshly excreted in the urine of patients with urinary tract infections and of isolates subcultured from the infected urine. Infection and Immunity 34:708-711.

Norden C W, Green G M, Kass E H 1968 Antibacterial mechanisms of the urinary bladder. Journal of Clinical Investigation 47:2689-2700.

Parsons C L, Stauffer C, Schmidt J D 1980 Bladder-surface glycosaminoglycans: an efficient mechanism of environmental adaptation. Science 208: 605-607.

Sivan Y, Griffel B, Medalia O, Aronson M 1982 Comparative histology of the mouse bladder following initial infection and re-infection with Escherichia coli. Journal of Pathology 138:353-364.

Stadler J, Aronson M, Medalia O, Griffel B 1980 Spontaneous bacterial clearance in experimental urinary tract infections in mice: Cellular aspects of the process. Nephron 25:288-292.

Weller T H, Coons A H 1954 Fluorescent antibody studies with agents of varicella and herpes zoster propagated in vitro. Proceedings of the Society for Experimental Biology and Medicine 86:789-794. 